\title{
COVID-19 and the Stock Markets: A Glance at the Initial Effects of the Pandemic ${ }^{1}$
}

\author{
Petar SORIĆ*
}

\begin{abstract}
The COVID-19 pandemic and consequent economic lockdown have triggered unprecedented economic uncertainty. The financial markets responded instantly, pricing in the uncertainty boom. This paper assesses the impact of anti-COVID social distancing measures on stock markets across the globe. Analyzing 60 world economies in a panel vector autoregression framework, we find that the stringency of social distancing interventions has a negative effect on market returns, but its character is strictly transitory and it fades away within 7 days. The magnitude of the pandemic in terms of recorded disease cases and deaths reveal a very similar pattern, causing a significant, but short-lived decline of stock prices. Our estimates reveal a considerable asymmetry in the identified interrelationships. Less developed markets seem to respond to the economic lockdown more intensively than highly developed economies.
\end{abstract}

Keywords: COVID-19 pandemic, economic uncertainty, stringency index, stock market, panel VAR

JEL Classification: C33, G15, G41

DOI: https://doi.org/10.31577/ekoncas.2021.05.02

\section{Introduction}

The outbreak of COVID-19 epidemic in November 2019 has been seen to rapidly spread from Wuhan (China) to more than 200 countries around the world, triggering a global pandemic. The magnitude of this pandemic has been such that many countries have recorded almost instantaneous local transmissions, compelling numerous national governments to enforce strict public health interventions,

\footnotetext{
* Petar SORIĆ, University of Zagreb, Faculty of Economics and Business Zagreb, Trg J.F. Kennedyja 6, 10000 Zagreb, Croatia; e-mail: psoric@efzg.hr

${ }^{1}$ This work has been fully supported by the Croatian Science Foundation under the project IP-2018-01-4189.
} 
travel restrictions, school closure, or even absolute quarantine in many examples. In certain time periods in the first quarter of 2020, about a half of world population was under some kind of curfew (Ramelli and Wagner, 2020).

This series of events has triggered a proliferation of epidemiological studies, clinical trials, and analyses of the genetics of severe acute respiratory syndrome coronavirus 2 (Xiang et al., 2020). However, the examination of socio-economic effects of the COVID-19 pandemic still remains in the domain of blogosphere, institutional reports and working papers. The pandemic has obviously generated extremely high economic uncertainty (Baker et al., 2020a), caused what seems to be an unprecedented stock market collapse (Baker et al., 2020b), and lead to massive unemployment (Chaney and Morath, 2020). Initial estimates go that far that Baker et al. (2020a) forecast a year-on-year decline in US GDP by as much as $11 \%$, owing about half of the contraction solely to COVID-induced uncertainty. ${ }^{2}$

Although the pandemic is still not near its end, it is vivid that the health crisis has transformed into a stock market decline, and spillover effects have been initiated to various sectors of the economy; transport, trade and tourism being among the ones hit the hardest by the imposed economic lockdown. Having that in mind, a proliferation of empirical research on the economic consequences of the corona crisis is about to emerge. We contribute to this strand of literature by focusing on the reactions of stock markets to the pandemic and related social distancing interventions. The reasons for choosing stock market returns as our target variable are twofold. First, macroeconomic aggregates are always published with a lag of several months, so it will take quite some time to unravel the complete macroeconomic effect of the pandemic. ${ }^{3}$ Stock market data, on the other hand, are of high frequency and can rapidly provide adequate data samples for sound econometric analysis. Second, the dynamic responses of financial markets to the uncertainty surrounding the pandemic have unveiled a very intriguing case study. Ramelli and Wagner (2020) segregate investors' reactions into three phases (Ramelli and Wagner, 2020). They refer to the first phase (January 2 to January 17) as the incubation period. The corona virus pandemic came as an exogenous shock to market participants, and only the best informed and sophisticated investors priced in the beginning of this health crisis. Early signs of pneumonia cases and first confirmed COVID-19 infections have stimulated a decline in US stock prices of only specific industries, such as Transportation and Energy. The outbreak

\footnotetext{
${ }^{2}$ Although the net economic effect of the COVID crisis was surely negative, some of its aspects have reinforced positive externalities, such as the digital revolution (Seetharaman, 2020; Keesara, Jonas and Schulman, 2020).

${ }^{3}$ At this point, let us revert to previously defined forecasts. One of those, introduced by World Bank representatives states a global influenza pandemic would decrease global GDP by $2 \%$ to even $5 \%$ within a year, depending on the considered scenario (Brahmbhatt, 2005).
} 
phase (January 20 to February 21) was characterized by a more substantial, general bearish sentiment. The companies exposed to China and international supply chains have now started to suffer tremendous stock price losses. According to Ramelli and Wagner (2020), the fever phase started on February 24, when Italy locked down the entire Lombardy region, and lasted until March 20. In this period, market volatility skyrocketed. On March 16, The Chicago Board Option Exchange's Volatility Index (VIX) has recorded its historic peak. Even the stock prices in Consumer Services, Food and Staples Retailing have now surged, indicating that markets have started to anticipate a harsh global economic turmoil.

In that sense, two important questions emerge. Did the COVID-19 shock significantly affect the global stock markets, and what did the dynamic response of the markets look like? To answer these questions, we assess a panel dataset referring to 60 world economies in order to examine the interrelationships between the magnitude of the COVID-19 pandemic, the stringency of policy interventions it caused, and aggregate stock market returns.

This paper adds to the literature in several aspects. The existing empirical studies of similar sort almost universally focus on the US stock markets (Alfaro et al., 2020; Baker et al., 2020b; Gerding, Martin and Nagler, 2020), or at best on a small subset of major markets and their reactions to the pandemic (Croce, Farroni and Wolfskeil, 2020; Gormsen, and Koijen, 2020). This paper attempts to provide a multi-country-perspective, building on a panel of 60 economies and making an effort to draw some conclusions on the globally prevailing influence of the pandemic on stock market returns. Further on, we utilize a panel vector autoregression (PVAR) model, enabling us to examine the temporal dynamics of the relationship between the severity of anti-COVID measures and stock market reactions. Our analysis reveals that the COVID-19 shock indeed exerts significant negative pressure to stock market returns, but it fades away rather quickly.

Finally, we segregate our dataset into separate subsamples according to the level of overall economic development and the level of financial market capitalization. Our analysis shows that the obtained results are relatively robust, although it seems that higher levels of financial and general economic development induce a less intensive stock market reaction.

The paper is conceptualized as follows. In the first section we provide a historical perspective and highlight the documented economic consequences of the 1918 influenza pandemic, which should provide adequate guidance for the potential impact of the current pandemic. The only robust conclusion from these studies is that the 1918 flu pandemic has triggered a significant, but short-lived effect on stock market returns. Therefore, we also try to shed some light on this issue for the COVID-19 pandemic. Section 2 briefly introduces the utilized dataset and 
panel VAR methodology, while section 3 presents the main empirical results. Finally, the last section concludes the paper, providing policy implications and guidance for future research.

\section{Pandemic and the Economy: Some Empirical Considerations}

The COVID-19 pandemic is not only a major threat to global health, but also an extraordinary exogenous shock to the economy. Its magnitude in terms of infection cases, mortality rates, and the imposed non-pharmaceutical policy interventions (social distancing, self-isolation, closure of schools and public institutions, national borders closure, etc.) has induced extreme negative externalities to the economic system. A sudden health shock has disrupted global supply chains in terms of both domestic and foreign trade, the imposed travel restrictions have halted tourism-related activities, caused supply and demand shocks for entrepreneurs, and consequently triggered a lockdown of many national economies around the globe. Needless to say, all of this has reflected in a stock market crash.

In economic terms, the outbreak of COVID-19 pandemic can be viewed as a case of classic Knightian uncertainty. Economic agents are suddenly faced with a situation in which they are unable to anticipate future events and cannot properly assess the likelihood of their occurrence (Knight, 1921).

The initial source of economic uncertainty related to the pandemic is purely epidemiological. Namely, the transmission mechanisms of the virus are still underexplored. Because of that, Ferguson et al. (2020) emphasize that non-pharmaceutical policy interventions (social distancing, school closures, travel restrictions, etc.) are likely to be kept in place until large stocks of antivirals are readily available to immunize the population. The educated guess of Ferguson et al. (2020) is that the vaccine will not be ready for mass usage until 2022. This type of setting acts as a driver of considerable economic uncertainty. According to the theoretical literature, uncertainty influences economic activity through several transmission channels. When faced with uncertainty, firms activate the wait and see mechanism (Bachmann and Bayer, 2013). Companies postpone irreversible activities such as hiring new employees, investing, and buying durable goods because these actions generate sunk costs. Bloom (2014) refers to this concept as the real options channel. Once the managers notice the decreased demand for their products and services (as customary for epidemics and the current economic lockdown), they accommodate by reducing wages and laying off employees. In the same manner, financial investors postpone their investments due to risk aversion. All of these forces combined generate a spiral effect, pushing the financial market downward. ${ }^{4}$ 
To unveil the potential economic effects of COVID-19 pandemic, this section relates the current pandemic to the 1918 influenza pandemic and reviews its documented economic consequences. This kind of comparative historical perspective should enrich our understanding of the phenomenon at hand and suggest some policy implications for the currently ongoing economic turmoil.

The 1918 influenza pandemic is chosen as a benchmark with potential implications for the current pandemic for several reasons. First of all, various studies use it to extrapolate the economic costs of modern-day influenza pandemic (Garrett, 2008). Following on that, it is the second deadliest pandemic in human history after the Plague (Bloom and Ajay, 1997). It had worldwide occurrence in the time when official national statistics (both medical and economic) have started to be closely monitored throughout the world, enabling sound data analytics. This has conditioned several thorough econometric studies of the economic effects of the influenza pandemic. Karlsson, Nilsson and Pichler (2014) find a causal link between the 1918 pandemic and lower capital returns in Sweden. Given that the pandemic was an exogenous supply shock to the labor market, they also expected a considerable increase in wages. However, this effect has not been recorded in the Swedish data, as opposed to the case of USA (Garrett, 2009).

Correia, Luck and Verner (2020) perform a particularly interesting study of non-pharmaceutical interventions due to the influenza pandemic and their economic impact in the USA. Within their causal identification strategy, they find the flu pandemic to be a source of sharp and significant reductions in manufacturing industry, stock of durable goods, and bank assets. Moreover, they find that cities that reacted sooner and introduced more rigorous policy interventions (social distancing, isolation of suspected cases and various forms of business restrictions) record faster economic growth once the pandemic is over. In that sense, these stringent policy interventions act as a buffer for the economy, not as its limiting factor; and the imposed dilemma between health and economic outcomes might be a false one after all.

Barro, Ursúa and Weng (2020) augment these single country analyses to a panel framework of 43 world countries, yielding a wider perspective on the issue at hand. They find that the influenza pandemic has caused an average GDP reduction of $6 \%$, accompanied by declines in consumption, stock market returns and short-term government bonds.

Garrett (2008) finds that local quarantines and economic lockdown have caused a hike in unemployment and significantly decreased the revenues of several economic sectors, especially services.

\footnotetext{
${ }^{4}$ Bloom (2014) also mentions two channels through which uncertainty can potentially positively affect the economy, the growth options model and the Oi-Hartman-Abel effect, but the prevailing empirical evidence goes in favor of the negative effects of uncertainty.
} 
Trying to summarize the inferences of above cited literature, several conclusions arise. First, the economic consequences of the pandemic seem to be of purely short-term character. Second, there is a very high level of uncertainty involved in the obtained estimations. The final economic effect of the intervention policies seems to range from purely negative (Karlsson, Nilsson and Pichler, 2014; Garrett, 2008; Barro, Ursúa and Weng, 2020) to even positive (Correia, Luck and Verner, 2020). Likewise, Karlsson, Nilsson and Pichler (2014) do not find a link to the Swedish labor market, whereas Garret (2009) does for the USA. The results seem to be highly dependent on the country of interest and the preferred methodological framework. Finally, the literature seems to robustly find only that the flu pandemic has triggered a short-term decline in stock market returns (Karlsson, Nilsson and Pichler, 2014; Barro, Ursúa and Weng, 2020).

This paper aims to simulate the economic effects of the current COVID-19 pandemic, taking into account the documented effects of the 1918 influenza pandemic. We focus on the well-established link between the pandemic and stock market developments. In line with the prevailing conclusions of the cited literature, we expect a significant negative relationship between the pandemic magnitude and daily stock market returns. Although we expect a purely short-run effect, we also allow for a long-run relationship between the two examined concepts. Our dataset and the chosen methodological approach are explained as follows.

\section{Data and Methodology}

Our empirical strategy aims at assessing the dynamic effects of COVID-19 pandemic on stock market returns. With that goal, we construct a panel dataset consisting of daily data for 60 countries. In particular, we analyze the daily number of new COVID-19 cases per country and the daily number of new deaths by COVID-19 per country. ${ }^{5}$ Both variables are extracted from Hale et al. (2020a,b). We also utilize the same database to extract the stringency index to quantify the severity of government responses to the COVID-19 pandemic. Being the focal explanatory variable in our framework, stringency index is explained in more detail in section 2.1.

Stock market returns are the target variable in our modelling strategy. Using the Thomson Reuters Eikon database, we extract national composite stock market indices for the 60 assessed economies.

\footnotetext{
${ }^{5}$ It should be highlighted that we assess the daily number of new cases/deaths instead of the cumulative (total) number of infections/deaths. Although the latter figures are commonly utilized in public debates on "flattening the epidemic curve", the underlying exponential growth of total infections/deaths makes these variables integrated of second order, which disables us to conduct empirical analysis such as panel vector autoregressions and cointegration tests.
} 
All variables except the stringency index are characterized by considerable amounts of missing data. This is particularly the case for stock market indices, due to weekends, national holidays, and trading halts. To circumvent this issue, we calculate a 5-day moving average of COVID-19 daily new cases, daily deaths, and stock market indices. A window length of 5 days was chosen to account for the largest number of consecutive missing data points in the analyzed panel. The assessed variables are denoted as follows: CASES, DEATHS, STRINGENCY, and STOCK. ${ }^{6}$

The dataset spans from 1 January to 16 April 2020 (yielding 107 daily observations), which should be adequate sample size to properly assess the temporal dimension of the observed interrelationships and incorporate time dynamics in the utilized econometric models.

\subsection{Stringency Index}

With the outbreak of COVID-19 pandemic, governments around the world have initiated a set of policy responses to combat the disease. These policy measures were tremendously heterogeneous in terms of the timing of their introduction, as well as their severity and total duration. This has triggered a wide public debate on the optimal set of measures not only in terms of health outcomes, but also in terms of preventing negative socio-economic externalities. To provide a quantitative foundation for rigorous academic evaluation of public policy responses to the pandemic, Hale et al. $(2020 a, b)$ have initiated the Oxford COVID-19 Government Response Tracker. They measure a variety of different policy interventions across the world. The most relevant ones are summarized in Table 1.

Hale et al. (2020a) meticulously collect data on each of these measures on a daily basis in more than 100 world countries. The composite stringency index is quantified in the following way.

For the first six constructs in Table 1 (each one except "Restrictions on international travel"), Hale et al. (2020b) add one to their recorded ordinal value if the stated policy intervention is general rather than targeted in terms of geographical scope. This way the "Public info campaign" component of the stringency index can range between 0 and 2, and the remaining six components can range between 0 and 3 . Then each component is rescaled by its maximum cross section value to obtain a numerical score between 0 and 100, and the composite stringency index is finally obtained as an arithmetic mean of these seven numerical scores. ${ }^{7}$

\footnotetext{
${ }^{6}$ We did not calculate natural logarithms of the examined variables since this would generate a very large number of missing values because the number of new daily COVID-19 cases/deaths is often equal to zero. Logarithm of zero is not defined.
} 
Table 1

Constructs Utilized for the Quantification of Stringency Index

\begin{tabular}{|c|c|}
\hline Construct & Ordinal value \\
\hline Closings of schools and universities & $\begin{array}{l}\text { 0-No measures } \\
\text { 1-Recommend closing } \\
\text { 2-Require closing }\end{array}$ \\
\hline Closings of workplaces & $\begin{array}{l}\text { 0-No measures } \\
\text { 1-Recommend closing } \\
\text { 2-Require closing }\end{array}$ \\
\hline Cancelling public events & $\begin{array}{l}\text { 0-No measures } \\
\text { 1-Recommend cancelling } \\
\text { 2-Require cancelling }\end{array}$ \\
\hline Closing of public transport & $\begin{array}{l}\text { 0-No measures } \\
\text { 1-Recommend closing } \\
\text { 2-Require closing }\end{array}$ \\
\hline Public info campaigns & $\begin{array}{l}\text { 0-No COVID-19 public info campaign } \\
\text { 1-COVID-19 public info campaign }\end{array}$ \\
\hline Restrictions on internal movement & $\begin{array}{l}\text { 0-No measures } \\
\text { 1-Recommend movement restriction } \\
\text { 2-Restrict movement }\end{array}$ \\
\hline Restrictions on international travel & $\begin{array}{l}\text { 0-No measures } \\
\text { 1-Screening } \\
\text { 2-Quarantine on high-risk regions } \\
\text { 3-Ban on high-risk regions }\end{array}$ \\
\hline
\end{tabular}

Source: Hale et al. (2020a).

\subsection{Panel VAR Model}

VAR models allow researchers to disentangle the dynamic interrelationships among the observed time series. Although the model originates from time series analysis, it has recently experienced several extensions in panel data frameworks. For example, Love and Zicchino (2006) introduced one of its first empirical applications. Lately, the model witnessed growing popularity and has often been applied in macroeconometric studies (e.g. Neuman, Fishback and Kantor, 2010; Head, Lloyd-Ellis and Sun, 2014). The model is given by equation (1):

$$
\begin{aligned}
& \boldsymbol{Y}_{i t}=\boldsymbol{Y}_{i t-1} \boldsymbol{A}_{1}+\boldsymbol{Y}_{i t-2} \boldsymbol{A}_{2}+\cdots+\boldsymbol{Y}_{i t-p} \boldsymbol{A}_{p}+\boldsymbol{u}_{i}+\boldsymbol{e}_{i t}, \\
& i \in\{1,2, \ldots, N\}, t \in\left\{1,2, \ldots, T_{i}\right\}
\end{aligned}
$$

\footnotetext{
${ }^{7}$ The methodological framework of Hale et al. (2020a) is based on converting ordinal scale variables to a composite indicator of ratio scale. This type of conversion has been extensively debated in the literature, with pro arguments mostly based on the utilitarian value and meaningfulness of conversion, and contra arguments established mainly on measurement theory (see e.g. Velleman and Wilkinson (1993) for a thorough review). Within the last few decades, several sophisticated statistical procedures of converting ordinal scale to ratio scale data have emerged (e.g. GrandbergRademacker, 2010), and many recent social survey studies have applied a similar approach to that of the Oxford COVID-19 Government Response Tracker (e.g. Gwartney et al., 2020; Coppedge et al., 2021). In that sense, Hale et al. (2020a) apply a relatively common quantification procedure for the social sciences, although not one without methodological limitations.
} 
where

$\boldsymbol{Y}_{i t} \quad-$ a vector of system variables,

$\boldsymbol{A}_{1}$ to $\boldsymbol{A}_{p}-(k \times k)$ matrices of parameters,

$\boldsymbol{u}_{i} \quad-$ a vector of panel fixed effects,

$\boldsymbol{e}_{i t} \quad-$ the idiosyncratic error terms.

The basic assumption of PVAR setup is that the model structure holds equally for all cross-section units in the panel. Since this assumption is rarely met in empirical research, the model allows for unobserved heterogeneity, i.e. fixed effects. The latter are correlated with the regressors due to lags of the dependent variables. To circumvent this issue, we utilize forward mean-differencing, also known as the Helmert procedure (Arellano and Bover, 1995). This procedure is particularly important since it eliminates any unobserved heterogeneity (such as specific political, structural economic or cultural idiosyncrasies of individual economies) that might have been correlated with the stringency of undertaken anti-COVID-19 measures.

We estimate equation (1) using the system GMM estimator (Arellano and Bover, 1995; Blundell and Bond (1998), which is a standard choice for PVAR estimations (Binder, Hsiao and Pesaran, 2005; Abrigo and Love, 2016).

Within such a framework, we adopt standard time series VAR techniques such as impulse response functions (IRFs) and forecasting error variance decomposition (Sims, 1980). IRFs represent the reaction of a particular variable to a $c e$ teris paribus shock in another variable in the PVAR system. In empirical research, it is unlikely that the variance-covariance matrix of error terms is diagonal, so it is necessary to apply some kind of a decomposition of the residuals to make them orthogonal (Love and Zicchino, 2006). The conventional procedure would be to apply Cholesky ordering, i.e. assume that the variables appearing earlier in the ordering are more exogenous and the ones appearing later are more endogenous. In other words, Cholesky ordering imposes a recursive causal chain, directed from the first variable to the last one, and not the other way around. In case of this study, the ordering was rather straightforward. Documented COVID-19 cases come first, affecting all other variables both contemporaneously and with a time lag. Recorded COVID-19 deaths come second, affecting both the stringency index and stock market indices. Stringency index is the third variable, followed by stock market indices as the most endogenous variable in the system.

The forecast error variance decomposition presents very similar information, but displayed in a somewhat different format. It decomposes the forecast error variance of a particular system variable to proportions attributable to each particular variable in the PVAR system. Just as for IRFs, its results depend on the employed Cholesky ordering. 
Our baseline model is a bivariate PVAR, comprising only the stringency index and stock market returns ("baseline VAR" hereinafter). In the next model specification, we add the number of COVID-19 cases and COVID-19 deaths as control variables ("PVAR with controls" hereinafter). The purpose of this model is not solely to inspect the stock market response to anti-COVID measures, but also to scrutinize the interplay between the recorded cases/deaths and the stringency index. In other words, we are interested to find out how persistently and how intensively national governments responded to the magnitude of the pandemic.

Additionally, we re-estimate the PVAR with controls for different subsamples of examined countries to question the robustness of the obtained results. We segment the panel into groups characterized by low/high financial development levels and low/high general development levels. One can easily postulate that more developed economies are more strongly integrated into global supply chains, which should imply that the former countries are more susceptible to the COVID-19 shock and the related social distancing policies. To empirically assess this hypothesis, we utilize the framework of Bayraktar (2014), who focuses on actual financial market capitalization in percent of GDP for a panel of countries even wider than the one analyzed in this study. Bayraktar (2014) defines the cut-off point for the low/high financial development level as the median share of market capitalization in GDP. We construct a dummy variable MARKETCAP, taking the value of one for countries with a high (above-median) level of financial market capitalization and 0 otherwise. Likewise, we construct a dummy variable DEVELOPED, equaling one for highly developed countries, and zero otherwise. The concept of highly developed countries refers to the OECD high income countries (see Bayraktar, 2014: 88 for details). The covered countries, as well as the main descriptive statistics of all assessed variables are given in online Appendix $1{ }^{8}$

\section{Empirical Results}

The first step of our estimation strategy entails unit root testing, since the result of this procedure conditions the preferred econometric model in future steps. We start by applying a battery of panel unit root tests: Im, Pesaran and Shin (2003), Fisher Augmented Dickey Fuller test (Choi, 2001), Breitung (Breitung, 2000; Breitung and Das, 2005), and Hadri (2000) test.

For variables in levels, the test equation including both trend and intercept is estimated, while the first differences of all variables are tested via an equation including only an intercept. The exception to that rule is Breitung test, which is

\footnotetext{
${ }^{8}$ Available at:

<https://www.sav.sk/journals/uploads/0531131005\%2021\%20Soric\%20Appendix\%201\%20(for\% 20online\%20publication).pdf $>$.
} 
conceptualized to always comprise both trend and an intercept in the test equation. The optimal number of lags in the test equation for the Im, Pesaran and Shin, Fisher Augmented Dickey Fuller and Breitung test is chosen according to the Schwarz information criterion. The obtained results are summarized in Table 2.

T a ble 2

Panel Unit Root Test Results

\begin{tabular}{|l|c|c|c|c|c|}
\hline \multicolumn{1}{|c|}{ Variable } & \multicolumn{5}{|c|}{ Test } \\
\hline & Im Pesaran Shin & Fisher & Levin Lin Chu & Breitung & Hadri \\
\hline & $\begin{array}{c}\text { Null } \\
\text { hypothesis: } \\
\text { All panels have a } \\
\text { unit root }\end{array}$ & $\begin{array}{c}\text { Null } \\
\text { hypothesis: } \\
\text { All panels have } \\
\text { a unit root }\end{array}$ & $\begin{array}{c}\text { Null } \\
\text { hypothesis: } \\
\text { All panels have } \\
\text { a unit root }\end{array}$ & $\begin{array}{c}\text { Null } \\
\text { hypothesis: } \\
\text { All panels have } \\
\text { a unit root }\end{array}$ & $\begin{array}{c}\text { Null } \\
\text { hypothesis: } \\
\text { All panels are } \\
\text { stationary }\end{array}$ \\
\hline STOCK & 0.9847 & 0.9998 & 0.0002 & 0.7989 & 0.0000 \\
DSTOCK & 0.0000 & 0.0000 & 0.0000 & 0.0000 & 0.1130 \\
STRINGENCY & 0.9836 & 0.9999 & 0.0000 & 0.6862 & 0.0000 \\
DSTRINGENCY & 0.0000 & 0.0000 & 0.0000 & 0.0000 & 0.0025 \\
CASES & 1.0000 & 0.6735 & 1.0000 & 1.0000 & 0.0000 \\
DCASES & 0.0000 & 0.0000 & 1.0000 & 1.0000 & 0.0000 \\
DEATHS & 1.0000 & 0.0000 & 1.0000 & 1.0000 & 0.0000 \\
DDEATHS & 0.0000 & 0.0000 & 1.0000 & 1.0000 & 0.0000 \\
\hline
\end{tabular}

Note: Table entries are p-values.

Source: Author's calculations.

The five assessed panel unit root tests are based on different methodological foundations, so the obtained results are not fully identical across tests. However, the relative majority of five utilized approaches indicates that all variables can be deemed integrated of order one. This notion is also backed up by graphical evidence presented in Figure 1.

Before proceeding with PVAR analysis, we first consider the possibility of a long run relationship between the observed variables. Using the Pedroni (1999; 2004) test, we were not able to reject the null hypothesis of no panel cointegration, regardless of the deterministic components (constant/trend) included in the model. ${ }^{9}$ Thus, we conclude that the effects of the pandemic on stock market developments are restricted to the short-term. We proceed by first differencing the data to prevent spurious regression issues, and specifying a PVAR model.

We choose the optimal lag length in equation (1) is set to one using the Andrews and $\mathrm{Lu}$ (2001) version of the Bayesian information criterion for GMM estimation, based on the Hansen's (1982) J-statistic of overidentifying restrictions. This result does not change for alternative model specifications (PVAR with controls and further specifications for high/low market capitalization and general development). ${ }^{10} \mathrm{We}$ interpret this as a corroboration of the short-term nature of COVID shock that supports the results of cointegration test.

\footnotetext{
${ }^{9}$ The results are left out here for the sake of brevity.
} 
Figure 1

Graphical Presentations of the Mean Values of Observed Variables across Countries

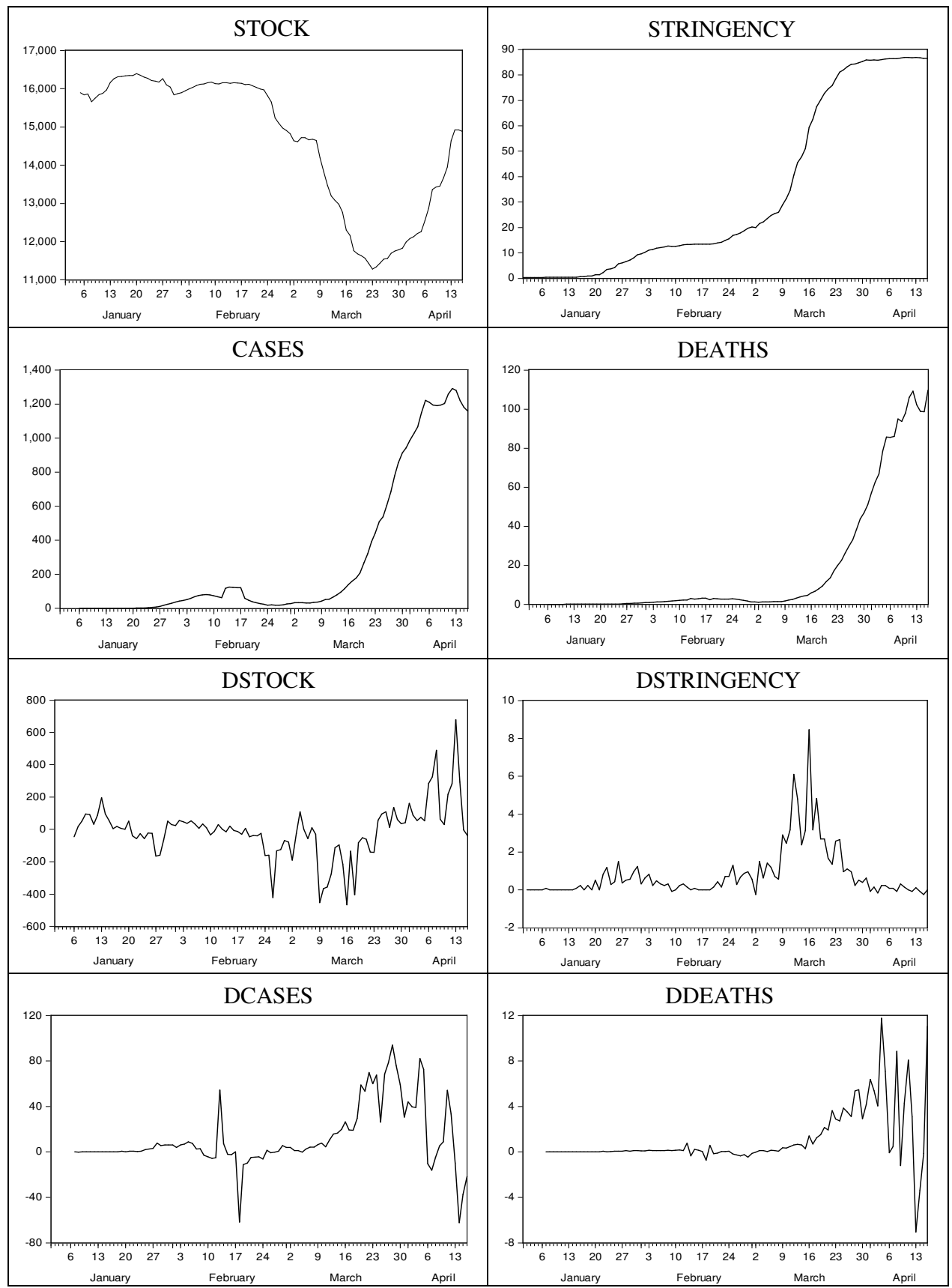

Source: Thomson Reuters Eikon database and Hale et al. (2020a,b) data.

\footnotetext{
${ }^{10}$ We tried to estimate all considered panel VAR models using two and three lags, but the results remained qualitatively the same.
} 
The analysis is continued with the estimation of IRFs. The dynamic responses of DSTOCK to a unit shock in DSTRINGENCY for various considered models are given in Figure 2.

Figure 2

\section{IRFs of DSTOCK to a Shock in DSTRINGENCY}

a) Baseline PVAR

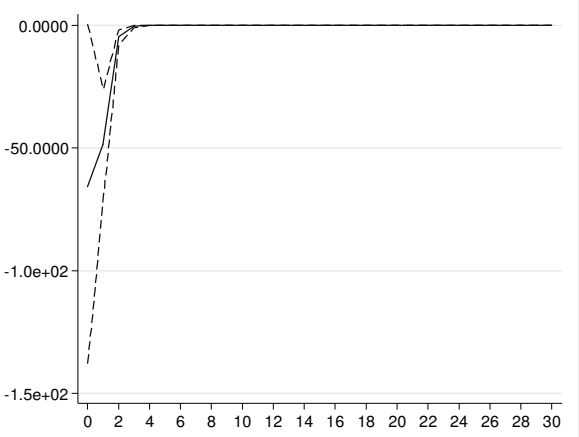

c) PVAR with controls (MARKETCAP=0)

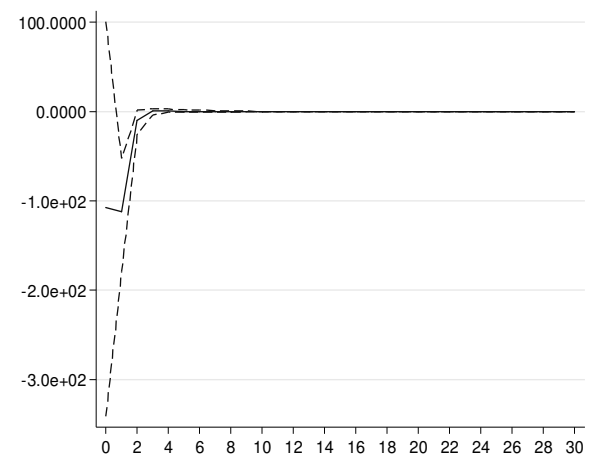

e) PVAR with controls (DEVELOPED=0)

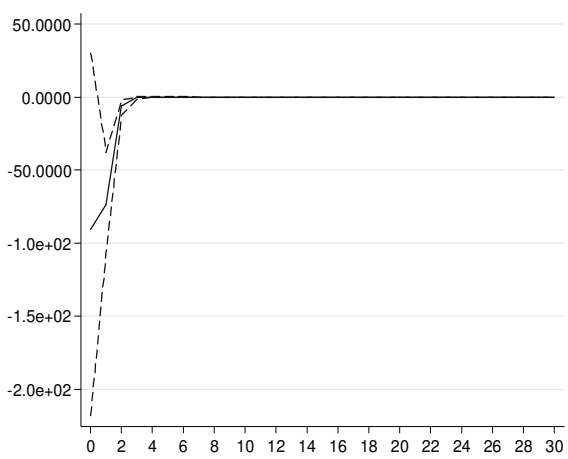

b) PVAR with controls

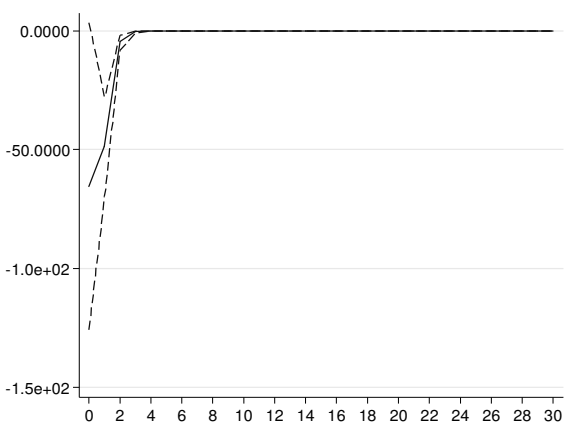

d) PVAR with controls (MARKETCAP=1)

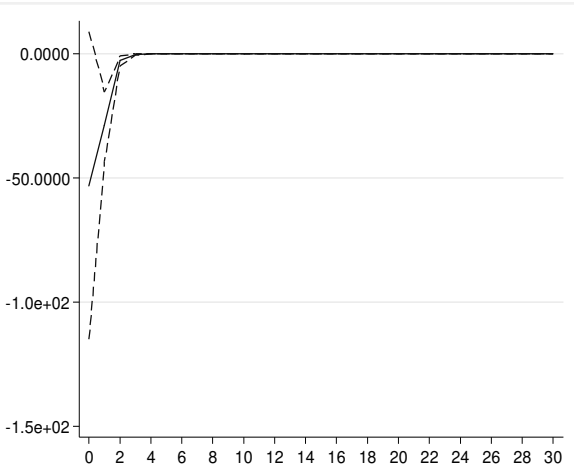

f) PVAR with controls (DEVELOPED $=1$ )

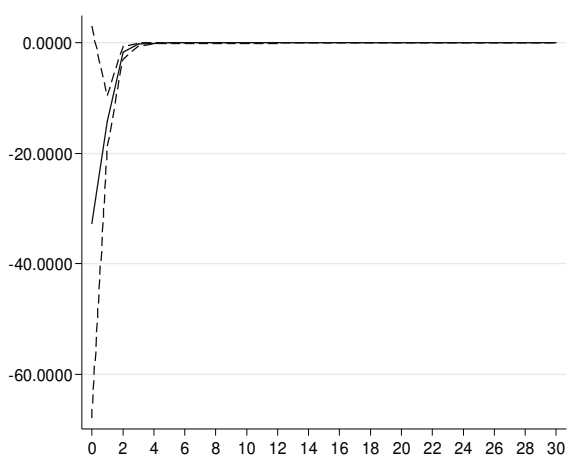

Source: Author's calculations. 
The obtained IRFs look remarkably similar in most considered PVAR models. Several inferences arise here. First, the stock markets respond to a stringency shock by significantly lowering market returns. For example, in the baseline PVAR, a one standard deviation shock in DSTRINGENCY on average feeds into a 50 index-points reduction of stock market indices one day after the stringency shock. This finding is well expected. It is in line with the findings of similar studies (Alfaro et al., 2020; Baker et al., 2020b; Croce, Farroni and Wolfskeil, 2020; Gormsen, and Koijen, 2020; Ramelli and Wagner, 2020). ${ }^{11}$ However, the documented influence of anti-COVID measures on stock market returns is extremely short-lived. In literally all considered models it fades away to zero in less than 7 days. Once again, this highlights the short-term nature of COVID-19 shock in terms of stock market returns. Although the global economy is heading towards a sharp recession, the financial markets do not seem to react as much. This result can also be related to the general finding that studies of the interconnectedness between stock market results and macroeconomic performance are rather inconclusive (Przekota et al., 2019).

Further on, our subsample analysis (panels c) to f) of Figure 2), reveals an intriguing pattern. Developed financial markets (panel d) of Figure 2) react to anti-COVID measures much more intensely than less developed markets (panel c), MARKETCAP=0). A somewhat similar finding is observed for low income economies (panel e) in comparison to those well-off (panel f). Namely, panel f) reveals a much milder effect than the one given in panel e). These results seem logical. Namely, stock market indices are forward-looking (Bachmann, Elstner and Sims, 2013, p. 243). In that context, we interpret our results as a sign that the prevailing market expectations about the economic losses due to COVID-19 restrictions are more pronounced in less developed economies. One might postulate that this holds because less developed countries adopted more severe anti-COVID measures. Indeed, our descriptive statistics reveal that lower income countries $(D E V E L O P E D=0)$ have a higher average value of the raw stringency index than high income countries (33.40 vs. 31.68). The same holds for countries with a lower level of market capitalization $(M A R K E T C A P=0)$ in comparison to MARKETCAP $=1$ economies ( 34.47 vs. 23.03).

The stated inferences can additionally be related to the conclusions of Ramelli and Wagner (2020), who find a direct link between international orientation of listed and the magnitude of decline in their stock prices. ${ }^{12}$ Less developed economies

\footnotetext{
${ }^{11}$ One should also notice that other similar exogenous shocks share a similar impact pattern on stock market returns. One of such patterns is attributable to e.g. terrorist attacks (Arin, Ciferri and Spagnolo, 2008).

${ }^{12}$ The co-movement of foreign trade and economic growth is one of the most explored issues in empirical macroeconomics. For a recent meta-analysis, corroborating the export led growth hypothesis, see Mokerjee (2006).
} 
are obviously more exposed to shocks in international supply chains, and as such they are more vulnerable to stringent social distancing measures, trade barriers and closing national borders, so they price that in their stock market expectations.

We should also highlight that this is not the only study finding the impact of COVID-19 to be heterogeneous across countries. For example, Gerding, Martin and Nagler (2020) conclude that the stock markets of highly indebted countries react more intensely to COVID-19 shocks. Similarly, Ru, Yang and Zou (2020) find that countries without documented cases of SARS disease in 2003 react to the current pandemic less strongly and with a considerable delay.

We are also interested in the responses of DSTOCK to the magnitude of COVID-19 pandemic itself. In that respect, Figure 3 presents the obtained impulse responses of DSTOCK to a shock in LCASES. The IRFs to a shock in DDEATHS were not found to be significant in most of the assessed PVAR models, so we do not report that results. It is vividly clear from Figure 3 that the impact of the pandemic magnitude is extremely similar to the effect of anti-COVID measures (shown in Figure 2). Again, the effect is negative and significant, but it fades away very quickly. In the end, Figure 4 reveals the time dynamics of governmental reactions to COVID outbreak.

As can be seen, the stringency of anti-COVID measures positively reacts to a shock in DCASES, but it has a rather short "memory".

Table 3 summarizes the results of forecasting error variance decomposition of DSTOCK for various considered PVAR models. The presented results refer to the 30 days forecasting horizon. Shorter horizons are not depicted since their results do not considerably deviate from those in Table 3.

T a b le 3

Forecasting Error Variance Decomposition of DSTOCK

\begin{tabular}{|l|c|c|c|c|c|c|}
\hline & \multicolumn{2}{|c|}{ Baseline PVAR } & \multicolumn{4}{c|}{ PVAR with controls } \\
\cline { 2 - 7 } & DSTRINGENCY & DSTOCK & DCASES & DDEATHS & DSTRINGENCY & DSTOCK \\
\hline Full sample & 0.0007 & 0.9993 & $5.89 \mathrm{e}-06$ & $3.68 \mathrm{e}-06$ & 0.0007 & 0.9993 \\
MARKETCAP=0 & 0.0010 & 0.9990 & $3.25 \mathrm{e}-05$ & 0.0002 & 0.0010 & 0.9988 \\
MARKETCAP =1 & 0.0006 & 0.9994 & $8.83 \mathrm{e}-06$ & $6.54 \mathrm{e}-06$ & 0.0006 & 0.9994 \\
DEVELOPED=0 & 0.0008 & 0.9992 & $1.82 \mathrm{e}-05$ & $8.99 \mathrm{e}-05$ & 0.0008 & 0.9991 \\
DEVELOPED =1 & 0.0012 & 0.9988 & $5.50 \mathrm{e}-05$ & $3.2 \mathrm{e}-05$ & 0.0012 & 0.9988 \\
\hline
\end{tabular}

Source: Author's calculations.

A glance at Table 3 reveals that the stringency of anti-COVID measures accounts only for a marginal share of DSTOCK variability. This inference is equally valid for bivariate and wider scope PVAR models, regardless of the chosen set of countries. In that context, it is clear that the assessed financial markets exhibit substantial persistence, such that even an economic lockdown cannot disrupt it. 
Strong persistence indeed is a characteristic feature of financial markets (Koutmos, Lee and Theodossiou, 1994; Bentes, 2014). Nevertheless, one caveat should be highlighted here. Ramelli and Wagner (2020) find that a wide scope of industries has recorded stock price declines in the fever phase of pandemic. They interpret this as a sign that a critical mass of investors has revised their expectations towards a severe global recession. At this point in time, such a scenario seems highly probable (Baker et al., 2020a), and would eventually entail a re-assessment of the results obtained in this study.

Figure 3

\section{IRFs of DSTOCK to a Shock in DCASES}

a) PVAR with controls

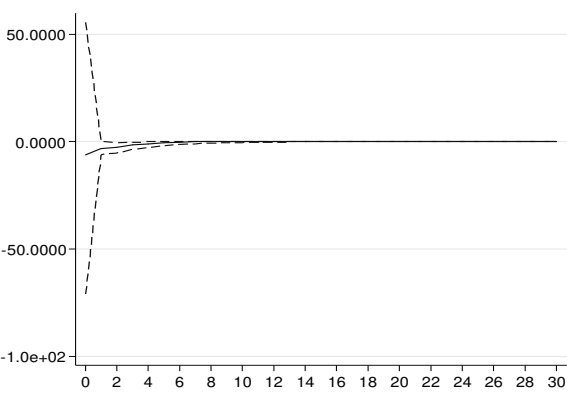

c) PVAR with controls (MARKETCAP=1)

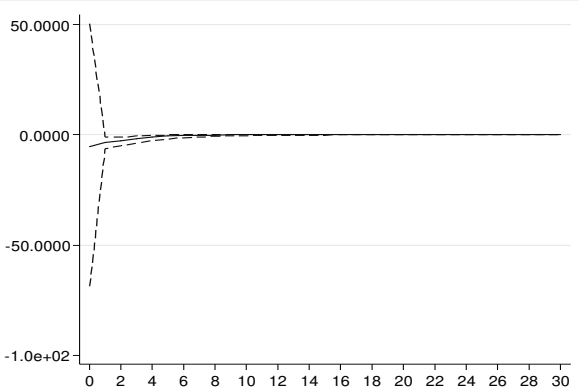

e) PVAR with controls (DEVELOPED=1)

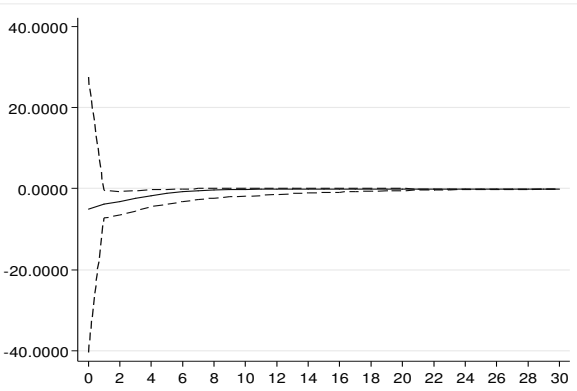

Source: Author's calculations. b) PVAR with controls (MARKETCAP=0)

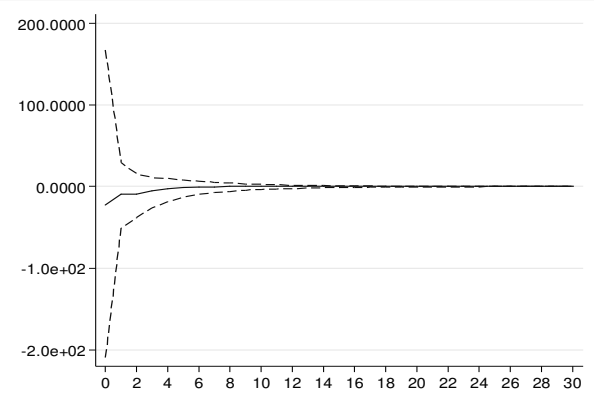

d) PVAR with controls (DEVELOPED=0)

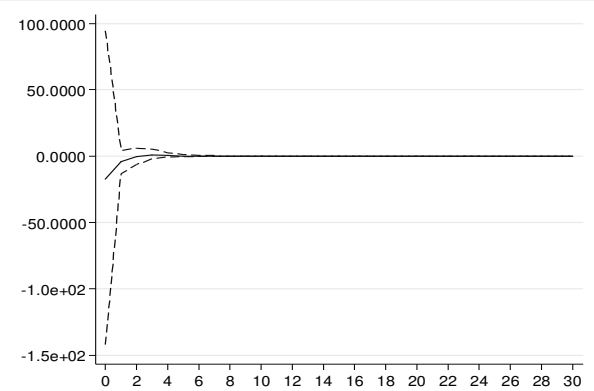


Figure 4

\section{IRFs of DSTRINGENCY to a Shock in DCASES}

a) PVAR with controls

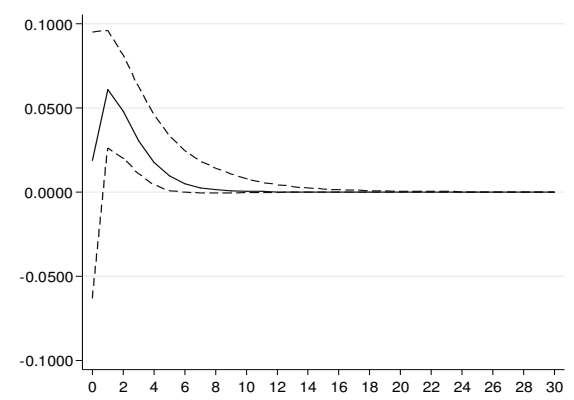

c) VAR with controls (MARKETCAP=1)

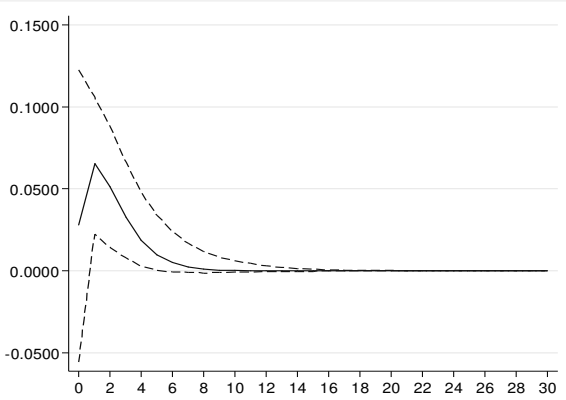

e) PVAR with controls (DEVELOPED=1)

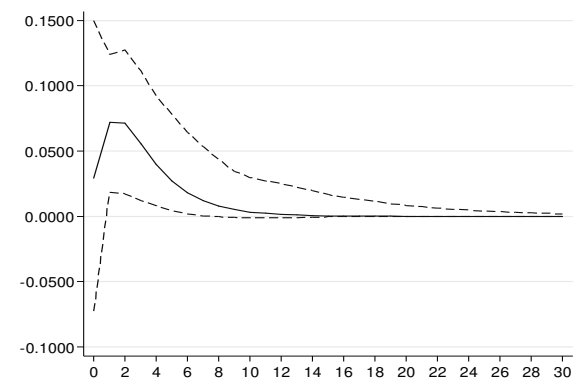

Source: Author's calculations. b) PVAR with controls (MARKETCAP $=0$ )

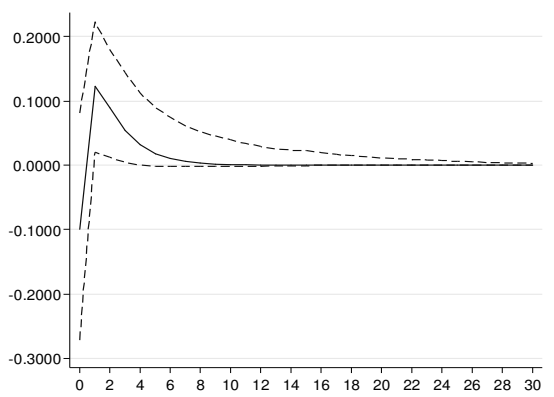

d) PVAR with controls (DEVELOPED=0)

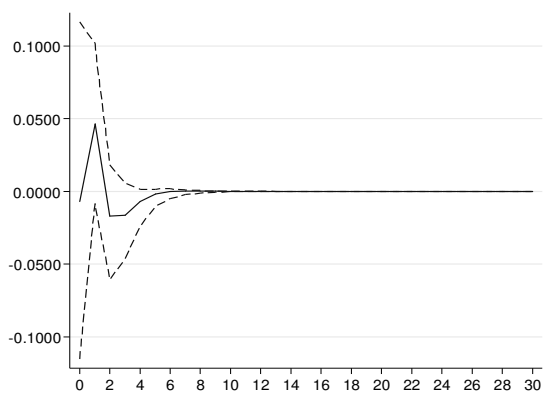

\section{Conclusion}

This paper empirically assesses the impact of COVID-19 pandemic and the related social distancing measures on aggregate stock market indices. To enable a global perspective on the issue at hand, we consider as much as 60 world economies in a PVAR framework. Our estimates reveal that the impact at hand is 
of strictly short-term nature, meaning that the pandemic constitutes a transitory shock to the financial markets. This finding is quite robust across model specifications. The financial markets recorded an upswing in April 2020, backed-up by quantitative easing programs, central bank interventions and strong fiscal stimulus packages (Morgan, 2020). However, interpreting the stated upturn as a sign that the stock markets are on a long-term growth track would be pure disaster myopia (Cornand and Gimet, 2014). At this point in time, forecasting the long run effects of COVID-19 on stock market returns would be a mainly speculative endeavor. Should a deep global recession emerge (and many analysts had anticipated it even prior to the COVID-19 pandemic, due to the USA-China trade war, Brexit and the general geopolitical instability), it would surely be reflected in the financial markets as well. Further on, our results demonstrate an obvious dichotomy between the financial markets and the real economy. Despite the fact that the real economy (hospitality and travel industry in particular) have experienced a major turmoil, the financial markets have mostly promptly bounced back after the initial blow of the crisis (Nicola et al., 2020). This can be related to the notion of Mann (2020) that the economic consequences of COVID-19 should be viewed through the real and financial lenses separately. In a similar vein, Haroon and Rizvi (2020) also advocate the same argument, finding that stock market indices related to a variety of industrial sectors were mostly unaffected by the COVID-19 panic, while sectors such as transportation, travel and leisure have experienced a considerable correction.

We apply particular attention to questioning the heterogeneity of the examined panel of countries, analyzing the robustness of our results for different subsamples of countries according to their development levels. We find that more developed markets react less strongly to the pandemic and the related social distancing measures. This result is interpreted by recognizing that stock market returns are a good proxy for the prevailing expectations of economic losses due to COVID-19. More complex and more developed economic systems obviously expect a less intensive impact of the pandemic. One of the potential reasons for this finding is that developed Western economies such as the USA, EU, and UK have introduced extremely generous financial aid packaged and job retention schemes (Nicola et al., 2020). Not all emerging economies had the financial capacity and the institutional strength to act in a similar manner. It should also be mentioned that many economic sectors have swiftly responded to the pandemic by transitioning to digital commerce (Seetharaman, 2020). Although we still lack rigorous international comparisons of the scope of digitalization shift, it would be expected that the process was more intensive in developed countries, mitigating the negative effects of the pandemic and stimulating market investors in those countries to expect only transitory stock corrections. 
In our opinion, the notion of COVID-induced digitalization is particularly worth of further research, especially because more stringent social distancing interventions were imposed in less developed countries. Shedding some light on the potential social and cultural determinants of the stringency of anti-COVID measures also seems as a potentially fruitful area of research.

This study is, of course, not without limitations. Analyzing a longer time span of data might capture the long-term socio-economic effects of the COVID-19 outbreak and the social distancing policies implemented by national governments. A long-term perspective is particularly important since the current outlook involves too much uncertainty, linked to the timing of developing a vaccine to fight the virus effectively, to the efficiency and persistence of social distancing interventions, to their influence on the business sector, etc. Further research is certainly needed on all of these topics.

\section{References}

ABRIGO, M. - LOVE, I. (2016): Estimation of Panel Vector Autoregressions in Stata. The Stata Journal, 16, No. 3, pp. 778 - 804. DOI: 10.1177/1536867X1601600314.

ANDREWS, D. W. K. - LU, B. (2001): Consistent Model and Moment Selection Procedures for GMM Estimation with Application to Dynamic Panel Data Models. Journal of Econometrics, 101, No. 1, pp. 123 - 164. DOI: 10.1016/S0304-4076(00)00077-4.

ALFARO, L. - CHARI, A. - GREENLAND, A. N. - SCHOTT, P. K. (2020): Aggregate and Firm-level Stock Returns during Pandemics, in Real Time. [National Bureau of Economic Research Working Paper, No. 26950.] DOI: 10.3386/w26950.

ARELLANO, M. - BOVER, O. (1995): Another Look at the Instrumental Variable Estimation of Error Component Models. Journal of Econometrics, 68, No. 1, pp. 29 - 51. DOI: 10.1016/0304-4076(94)01642-D.

ARIN, K. P. - CIFERRI, D. - SPAGNOLO, N. (2008): The Price of Terror: The Effects of Terrorism on Stock Market Returns and Volatility. Economics Letters, 101, No. 3, pp. $164-167$. DOI: 10.1016/j.econlet.2008.07.007.

BACHMANN, R. - BAYER, C. (2013): 'Wait-and-See' Business Cycles? Journal of Monetary Economics, 60, No. 6, pp. 704 - 719. DOI: doi.org/10.1016/j.jmoneco.2013.05.005.

BACHMANN, R. - ELSTNER, S. - SIMS, E. R. (2013): Uncertainty and Economic Activity: Evidence from Business Survey Data. American Economic Journal: Macroeconomics, 5, No. 2, pp. 217 - 249. DOI: 10.1257/mac.5.2.217.

BAKER, S. - BLOOM, N. - DAVIS, S. J. - TERRY, S. J. (2020a): COVID-induced Economic Uncertainty. [National Bureau of Economic Research Working Paper 26983.] DOI: $10.3386 / \mathrm{w} 26983$.

BAKER, S. - BLOOM, N. - DAVIS, S. J. - KOST, K. - SAMMON, M. - VIRATYOSIN, T. (2020b): The Unprecedented Stock Market Reaction to COVID-19. Covid Economics: Vetted and Real-Time Papers 1, 3 April. DOI: 10.3386/w26945.

BARRO, R. J. - URSÚA, J. F. - WENG, J. (2020): The Coronavirus and the Great Influenza Pandemic: Lessons from the "Spanish Flu" for the Coronavirus's Potential Effects on Mortality and Economic Activity. [National Bureau of Economic Research Working Paper 26866.] DOI: $10.3386 /$ w26866. 
BAYRAKTAR, N. (2014): Measuring Relative Development Level of Stock Markets: Capacity and Effort of Countries. Borsa Istanbul Review, 14, No. 2, pp. 79 - 95. DOI: 10.1016/j.bir.2014.02.001.

BENTES, S. R. (2014): Measuring Persistence in Stock Market Volatility Using the FIGARCH Approach. Physica A, 408, pp. 190 - 197. DOI: 10.1016/j.physa.2014.04.032.

BINDER, M. - HSIAO, M. - PESARAN, M. H. (2005): Estimation and Inference in Short Panel Vector Autoregressions with Unit Roots and Cointegration. Econometric Theory, 21, No. 4, pp. 795 - 837. DOI: $10.1017 /$ S0266466605050413.

BLOOM, N. (2014): Fluctuations in Uncertainty. Journal of Economic Perspectives, 28, No. 2, pp. 153 - 176. DOI: 10.1257/jep.28.2.153.

BLOOM, D. - AJAY, M. (1997): AIDS, Flu, and the Black Death: Impacts on Economic Growth and Well-Being. In: BLOOM, D. and GOODWIN, P. (eds): The Economics of HIV and AIDS: The Case of South and Southeast Asia. Delhi: Oxford University Press, pp. $22-52$.

BLUNDELL, R. - BOND, S. (1998): Initial Conditions and Moment Restrictions in Dynamic Panel Data Models. Journal of Econometrics, 87, No. 1, pp. 115 - 143. DOI: 10.1016/S0304-4076(98)00009-8.

BRAHMBHATT, M. (2005): Avian Influenza: Economic and Social Impacts. Speech. Washington DC: World Bank. [Cit. 25. 04. 2020.] Available at: <https://www.worldbank.org/content/dam/Worldbank/document/HDN/Health/AHISocioImpacts.pdf>.

BREITUNG, J. (2000): The Local Power of Some Unit Root Tests for Panel Data. In: BALTAGI, B. H. (ed.): Advances in Econometrics, Volume 15: Nonstationary Panels, Panel Cointegration, and Dynamic Panels. Amsterdam: JAI Press, pp. $161-178$.

BREITUNG, J. - DAS, S. (2005): Panel Unit Root Tests Under Cross-sectional Dependence. Statistica Neerlandica, 59, No. 4, pp. 414 - 433. DOI: 10.1111/j.1467-9574.2005.00299.x.

CHANEY, S. - MORATH, E. (2020): Record 6.6 Million Americans Sought Unemployment Benefits Last Week. Wall Street Journal. [Cit. 23. 04. 2020.] Available at: $<$ https://www.wsj.com/articles/another-3-1-million-americans-likely-sought-unemploymentbenefits-last-week-11585819800>.

CHOI, I. (2001): Unit Root Tests for Panel Data. Journal of International Money and Finance, 20, No. 2, pp. 249 - 272. DOI: 10.1016/S0261-5606(00)00048-6.

COPPEDGE, M. - GERRING, J. - KNUTSEN, C. H. - LINDBERG, S. I. - TEORELL, J. - MARQUARDT, K. L. - MEDZIHORSKY, J. - PEMSTEIN, D. - ALIZADA, N. - GASTALDI, L. - HINDLE, G. - PERNES, J. - VON RÖMER, J. - TZELGOV, E. - WANG, Y. - WILSON, S. (2021): V-Dem Methodology v11.1. [Varieties of Democracy (V-Dem) Project.] Available at: <https://www.v-dem.net/en/data/reference-material-v11/>.

CORNAND, C. - GIMET, C. (2014): The 2007 - 2008 financial Crisis: Is There Evidence of Disaster Myopia? Emerging Markets Review, 13, No. 3, pp. 301 - 315. DOI: 10.1016/j.ememar.2012.02.001.

CORREIA, S. - LUCK, S. - VERNER, E. (2020): Pandemics Depress the Economy, Public Health Interventions Do Not: Evidence from the 1918 Flu. [Cit. 30. 03. 2020.] Available at: $<$ https://ssrn.com/abstract=3561560>.

CROCE, M. M. - FARRONI, P. - WOLFSKEIL, I. (2020): When the Markets Get COVID: Contagion, Viruses, and Information Diffusion. [Cit. 23. 03. 2020.] Available at: <https://ssrn.com/abstract=3560347>.

FERGUSON, N. M. - LAYDON, D. - NEDJATI-GILANI, G. - IMAI, N, - AINSLIE, K. BAGUELIN, M. -BHATIA, S. - BOONYASIRI, A. - CUCUNUBÁ, Z. - CUOMO-DANNENBURG, G. - DIGHE, A. (2020): Impact of Non-pharmaceutical Interventions (NPIs) to Reduce COVID-19 Mortality and Healthcare Demand. London: Imperial College COVID-19 Response Team. [Cit. 26. 06. 2020.] Available at: <https://www.imperial.ac.uk/media/imperial-college/ medicine/sph/ide/gida-fellowships/Imperial-College-COVID19-NPI-modelling-16-032020.pdf >. 
GARRETT, T. A. (2008): Pandemic Economics: the 1918 Influenza and Its Modern-day Implications. Federal Reserve Bank of St. Louis Review, 90, March, pp. 74 - 94. DOI: $10.20955 /$ r.90.74-94.

GARRETT, T. A. (2009): War and Pestilence as Labor Market Shocks: US Manufacturing Wage Growth 1914 - 1919. Economic Inquiry, 47, No. 4, pp. 711 - 725. DOI: $10.1111 /$ j.1465-7295.2008.00137.x.the

GERDING, F. - MARTIN, T. - NAGLER, F. (2020): The Value of Fiscal Capacity in the Face of a Rare Disaster. [Cit. 10. 04. 2020.] Available at: 〈https://ssrn.com/abstract=3572839>.

GORMSEN, N. J. - KOIJEN, R. S. J. (2020): Coronavirus: Impact on Stock Prices and Growth Expectations. The Review of Asset Pricing Studies, 10, No. 4, pp. 574 - 597. DOI: $10.1093 / \mathrm{rapstu} / \mathrm{raaa} 013$.

GRANDBERG-RADEMACKER, J. S. (2010): An Algorithm for Converting Ordinal Scale Measurement Data to Interval/Ratio Scale. Educational and Psychological Measurement, 70, No. 1, pp. 1 - 17. DOI: 10.1177/0013164409344532.

GWARTNEY, J. - LAWSON, R. - HALL, J. - MURPHY, R. (2020): Economic Freedom of the World: 2020 Annual Report. Vancouver: Fraser Institute. [Cit. 23. 4. 2021.] Available at: <https://www.fraserinstitute.org/studies/economic-freedom-of-the-world-2020-annual-report>.

HADRI, K. (2000): Testing for Stationarity in Heterogeneous Panel Data. Econometrics Journal, 3, No. 2, pp. 148 - 161. DOI: 10.1111/1368-423X.00043.

HANSEN, L. P. (1982): Large Sample Properties of Generalized Method of Moments Estimators. Econometrica, 50, No. 4, pp. 1029 - 1054.

HEAD, A. - LLOYD-ELLIS, H. - SUN, H. (2014): Search, Liquidity, and the Dynamics of House Prices and Construction. American Economic Review, 104, No. 4, pp. 1172 - 1210. DOI: 10.1257/aer.104.4.1172.

HALE, T. - PETHERICK, A. - PHILLIPS, T. - WEBSTER, S. (2020a): Variation in Government Responses to COVID-19. [Working Paper.] Oxford: Blavatnik School of Government. [Cit. 23. 4. 2020.] Available at: 〈www.bsg.ox.ac.uk/covidtracker〉.

HALE, T. - WEBSTER, S. - PETHERICK, A. - PHILLIPS, T. - KIRA, B. (2020b): Oxford COVID-19 Government Response Tracker. Oxford: Blavatnik School of Government.

HAROON, O. - RIZVI, S. A. (2020): COVID-19: Media Coverage and Financial Markets Behavior a Sectoral Inquiry. Journal of Behavioral and Experimental Finance, 27, No. 100343. DOI: 10.1016/j.jbef.2020.100343.

IM, K. S. - PESARAN, M. H. -SHIN, Y. (2003): Testing for Unit Roots in Heterogeneous Panels. Journal of Econometrics, 115, No. 1, pp. 53 - 74. DOI: 10.1016/S0304-4076(03)00092-7.

KARLSSON, M. - NILSSON, T. - PICHLER, S. (2014): The Impact of the 1918 Spanish Flu Epidemic on Economic Performance in Sweden: An Investigation into the Consequences of an Extraordinary Mortality Shock. Journal of Health Economics, 36, pp. 1 - 19. DOI: 10.1016/j.jhealeco.2014.03.005.

KEESARA, S. - JONAS, A. M. D. - SCHULMAN, K. M. D. (2020): Covid-19 and Health Care's Digital Revolution. The New England Journal of Medicine, Perspectives, 382, No. 23, pp. e82(1) - e82(3). DOI: 10.1056/NEJMp2005835.

KNIGHT, F. H. (1921): Risk, Uncertainty, and Profit. Boston, MA: Hart, Schaffner \& Marx, Houghton Mifflin Company.

KOUTMOS, G. - LEE, U. - THEODOSSIOU, P. (1994): Time-varying Betas and Volatility Persistence in International Stock Markets. Journal of Business Economics, 4, No. 2, pp. $101-112$. DOI: 10.1016/0148-6195(94)90004-3.

LEVIN, A. - LIN, C. F. - CHU, C.-S. J. (2002): Unit Root Tests in Panel Data: Asymptotic and Finite-sample Properties. Journal of Econometrics, 108, No. 1, pp. 1 - 24. DOI: 10.1016/S0304-4076(01)00098-7.

LOVE, I. - ZICCHINO, L. (2006): Financial Development and Dynamic Investment Behavior: Evidence from Panel VAR. Quarterly Review of Economics and Finance, 46, No. 2, pp. 190 - 210. DOI: 10.1016/j.qref.2005.11.007. 
MANN, C. L. (2020): Real and Financial Lenses to Assess the Economic Consequences of COVID-19. In: BALDWIN, R. and di MAURO, B. W.: Economics in the Time of COVID-19. London: CEPR Press, pp. $81-86$.

MOKERJEE, R. (2006): A Meta-analyis of the Export Growth Hypothesis. Economics Letters, 91, No. 3, pp. 395 - 401. DOI: 10.1016/j.econlet.2005.12.020.

MORGAN, J. P. (2020): What Will the Recovery Look Like from The COVID-19 Recession? [Cit. 1. 5. 2021.] Available at: <https://www.jpmorgan.com/global/research/2020-covid19-recession-recovery>.

NEUMANN, T. C. - FISHBACK, P. V. - KANTOR, S. (2010): The Dynamics of Relief Spending and the Private Urban Labor Market during the New Deal. Journal of Economic History, 70, No. 1, pp. $195-220$.

NICOLA, M. - ALSAFI, Z. - SOHRABI, C. - KERWAN, A. - JABIR, A. A. - IOSIFIDIS, C. AGHA, M. - AGHA, R. (2020): The Socio-economic Implications of the Coronavirus Pandemic (COVID-19): A Review. International Journal of Surgery, 78, pp. 185 - 193. DOI: $10.1016 /$ j.ijsu.2020.04.018.

PEDRONI, P. (1999): Critical Values for Cointegration Tests in Heterogeneous Panels with Multiple Regressors. Oxford Bulletin of Economics and Statistics, 61, No. S1, pp. 653 - 670. DOI: $10.1111 / 1468-0084.0610$ s1653.

PEDRONI, P. (2004): Panel Cointegration: Asymptotic and Finite Sample Properties of Pooled Time Series Tests with an Application to the PPP Hypothesis. Econometric Theory, 20, No. 3 , pp. 597 - 625. DOI: 10.1017/S0266466604203073.

PRZEKOTA, G. - REMBEZA, J. - MENTEL, G. - SZETELA, B. (2019): The Relationship between the Stock Market and the Economy: Evidence from Central and Eastern European Countries. Transformations in Business \& Economics, 18, No. 2A, pp. 397 - 415.

RAMELLI, S. - WAGNER, F. (2020): Feverish Stock Price Reactions to COVID-19. The Review of Corporate Finance Studies, 9, No. 3, pp. 622 - 655. DOI: 10.1093/rcfs/cfaa012.

RU, H. - YANG, E. - ZOU, K. (2020): What Do We Learn from SARS-CoV-1 to SARS-CoV-2: Evidence from Global Stock Markets. [Cit. 6. 4. 2021] Available at: $<$ https://ssrn.com/abstract $=3569330>$.

SEETHARAMAN, P. (2020): Business Models Shift: Impact of COVID-19. International Journal of Information Management, 54, No. 102173. DOI: 10.1016/j.ijinfomgt.2020.102173.

SIMS, C. (1980): Macroeconomics and Reality. Econometrica, 48, No. 1, pp. $1-48$. DOI: $10.2307 / 1912017$.

VELLEMAN, P. F. - WILKINSON, L. (1993): Nominal, Ordinal, Interval, and Ratio Typologies Are Misleading. American Statistician, 47, No. 1, pp. $65-72$. DOI: 10.1080/00031305.1993.10475938.

XIANG, Y. T. - LI, W. - ZHANG, Q. - JIN, Y. - RAO, W. W. - ZENG, L. N. - LOK, G. K. I. CHOW, I. H. I. - CHEUNG, T. - HALL, B. J. (2020): Timely Research Papers about COVID-19 in China. The Lancet, 395, No. 10225, pp. 684 - 685. DOI: 10.1016/S0140-6736(20)30375-5. 